\title{
Proposição de modelo para gestão de custos adicionais na concessão de empréstimo: o caso de cooperativas de crédito e o fator risco
}

\begin{abstract}
Maicon Zanette Graduação em Ciências Contábeis pela Universidade Federal de Santa Catarina UFSC Rua Tenente Silveira, 94. Florianópolis/SC. CEP: 88010-300 E-mail:maiconaz@gmail.com

Cristiano Nascimento Bacharelado em Ciências Contábeis pela Universidade Federal de Santa Catarina UFSC Rua Coronel Vicente, 444, ap. 43. Porto Alegre/RS. CEP: 90030-040 E-mail: cristiano.nascimento.cont@gmail.com

Luiz Alberton Doutorado em Engenharia de Produção pela Universidade Federal de Santa Catarina UFSC Professor da Universidade Federal de Santa Catarina - UFSC Campus Trindade (CSE). Florianópolis/SC. CEP: 88040-900 E-mail: alberton@cse.ufsc.br
\end{abstract}

\section{RESUMO}

A gestão dos custos assume papel relevante em virtude da acirrada competitividade no sistema financeiro brasileiro, ainda mais no segmento em que atuam as cooperativas de crédito. O presente estudo apresenta uma proposição de modelo para mensurar custos adicionais na concessão de empréstimo pessoal, no intuito de prevenir perdas permanentes, efetivas ou potenciais aos processos financeiros das cooperativas de crédito. Para tanto, fez-se um estudo exploratório-descritivo, com abordagem qualitativa dos dados, realizado por meio de um estudo de caso em uma cooperativa de crédito com fortes traços de práticas de controle na concessão de empréstimo pessoal aos associados. Como resultado, apresenta-se a proposição de mensuração dos "custos adicionais de provisão", mediante controle extra-contábil, como alternativa de uma melhora na gestão dos custos existentes nas etapas de avaliação e concessão do empréstimo pessoal.

Palavras-chave: Cooperativas de crédito. Mensuração de custos. Empréstimo pessoal.

Proposal of model for management of incidental costs in the concession of loan: the case of credit cooperatives and the factor risk 
Proposição de modelo para gestão de custos adicionais na concessão de empréstimo: o caso de cooperativas de crédito e o fator risco

Maicon Zanette, Cristiano Nascimento, Luiz Alberton

\section{ABSTRACT}

The costs management takes relevant role due to instigated competition in Brazilian Financial System, detaching on the line of work that credit cooperatives take place. This study allows to create a model proposition to measure additional costs in the giving a personal loan, aiming to prevent permanent losses, effective or potential to the financial processes in credit cooperatives. In order to achieve this, an exploratory-descriptive study was made, with qualitative approach of data, set by a case study in a credit cooperative with strong traces of control practice when setting personal loans to their partners. As a result, a measuring proposition of "provision additional costs" was presented, considering extra-accountant control, as alternative of an improvement in the costs management existent on evaluation phases and setting personal loan.

Key Words: Credit Cooperative. Cost measuring. Personal Loan.

\section{INTRODUÇÃO}

No ambiente organizacional do segmento financeiro atuam bancos múltiplos, comerciais, de investimento, entre outros. Também se encontram as cooperativas de crédito, as quais, apesar de limitações legais na concessão e obtenção de créditos e da pequena fatia de mercado, destacam-se no cenário financeiro com expressivos crescimentos anuais.

Não data de muito tempo a abertura efetiva do mercado financeiro à atuação de cooperativas de crédito de livre adesão de cooperados, antes mesmo das normas impostas pelo Banco Central do Brasil (BACEN), o qual regulamentou a possibilidade de qualquer pessoa associar-se a uma cooperativa, que geralmente fica limitada a atuar em determinados ramos de atividades ou de profissionais e somente nestes.

Também a criação do Plano Contábil das Instituições do Sistema Financeiro Nacional (COSIF) em 1987 uniformizou os procedimentos contábeis das instituições financeiras. Mas a gestão dos custos ficou a mercê de critérios de controle extracontábil individual e particularmente a cada entidade, pois a evidenciação prevista no COSIF alude somente a receitas e despesas.

Nesse contexto, este estudo objetiva propor um modelo de mensuração para custos adicionais de provisão para operações de empréstimo pessoal, baseado na 
Proposição de modelo para gestão de custos adicionais na concessão de empréstimo: o caso de cooperativas de crédito e o fator risco

Maicon Zanette, Cristiano Nascimento, Luiz Alberton

identificação de atividades e riscos que possam gerar custos, em uma cooperativa de crédito.

De forma complementar, contribui no sentido de demonstrar por meio da contabilização permitida em normas vigentes no Brasil, o benefício da constituição excedente, a fim de se prevenir perdas permanentes, efetivas ou potenciais, que possam ocorrer aos processos financeiros das cooperativas de crédito.

Por sua vez, o respaldo legal vigente em relação às instituições financeiras brasileiras quanto à gestão dos custos, limita-se somente à contabilização da ocorrência de despesas. Porém, ressalta-se a proposição deste estudo, direcionado a uma melhor gestão dos custos, com vistas a controles de fins gerenciais. Nesse sentido, destaca-se a importância do estudo em função da carência, no meio acadêmico, de trabalhos relacionados a entidades não industriais, especialmente em se tratando de cooperativas de crédito, em relação à mensuração de custos incorridos na produção de serviços financeiros.

\section{REFERENCIAL TEÓRICO}

Como referência inicial deste estudo, conceitua-se temas relacionados ao cooperativismo de crédito, os custos inerentes aos processos em cooperativas de crédito e, por fim, considerações acerca de controle interno e riscos de crédito.

\subsection{Cooperativismo de Crédito}

Os conceitos e princípios doutrinários pré-existentes do cooperativismo fundamentam-se, na grande maioria, no propósito da cooperação e colaboração de membros de determinado grupo econômico, social ou afim, em detrimento de um fim único, seja na geração produtiva ou na forma de gerar renda e agregar valor aos esforços despendidos.

Com isso pode-se deduzir a prevalência do ato de cooperar, conceituado pela ORGANIZAÇÃO DAS COOPERATIVAS DO ESTADO DE SANTA CATARINA - OCESC (2004), como uma associação de pessoas com interesses comuns, organizadas 
Proposição de modelo para gestão de custos adicionais na concessão de empréstimo: o caso de cooperativas de crédito e o fator risco

Maicon Zanette, Cristiano Nascimento, Luiz Alberton

economicamente e de forma democrática, com participação voluntária, prezando a igualdade de deveres e direitos para a execução de atividades, operações ou serviços.

Este raciocínio advém nas cooperativas com premissa da constituição com base na autogestão da cooperação, princípios democráticos, estrutura horizontal e baixos custos de transação, com poucas barreiras para introduzir novos membros, fazendo com que eles se auto-organizem em busca de um objetivo comum (JUNQUEIRA; TREZ, 2005).

Destarte, por meio do cooperativismo as pessoas passam a descobrir o potencial coletivo, desenvolvendo valores e atitudes que contribuem para o benefício mútuo, em contraponto à hegemonia do capitalismo, doutrinas, princípios e movimentos contrários à liberdade coletiva.

O cooperativismo no Brasil teve sua origem nas primeiras cooperativas de consumo de Limeira, São Paulo (1891), no Rio de Janeiro (1894) e em Pernambuco, na cidade de Camaragibe (1895), entre outras, mas todas organizadas por segmentos da classe média urbana, de empregados de empresas privadas e de funcionários públicos (SIQUEIRA, 2001).

O cooperativismo de crédito surgiu por intermédio do padre suíço Teodoro Amstad em 1902 na cidade da Nova Petrópolis - RS, sendo baseado no modelo de Raiffeisen. Tal intuito destaca-se pelo sucesso com a criação de quatorze cooperativas entre 1902 e 1923, e mais vinte e seis entre 1923 e 1938, segundo afirma Pinho (1976). Seguindo o mesmo pensamento, surgiram cooperativas do tipo Luzzatti, influenciadas pelos imigrantes italianos, instaladas na região Sudeste/Sul e posteriormente nas demais regiões do país.

Com a reforma bancária prevista na Lei $n^{0} 4.595$, de 1964, e as normas de política financeira do Governo Federal, o cooperativismo de crédito começou a decair ocasionando uma reestruturação de todo o sistema cooperativista. $O$ tratamento dado pelo governo brasileiro às cooperativas atenuou-se somente a partir de 1995, por meio de algumas resoluções. Todavia, o ano de 2003 representou verdadeiramente a abertura do cooperativismo de crédito potencializada pela Resolução $n^{\circ} 3.106 / 2003$ do 
Proposição de modelo para gestão de custos adicionais na concessão de empréstimo: o caso de cooperativas de crédito e o fator risco

Maicon Zanette, Cristiano Nascimento, Luiz Alberton

BACEN, a qual permitiu a criação de cooperativas de crédito de livre admissão de associados, por micros e pequenos empresários e empreendedores.

As cooperativas de crédito são instituições financeiras, constituídas como sociedades de pessoas, com firma e natureza jurídica próprias, de natureza civil, sem fins lucrativos, com o objetivo de propiciar crédito e prestar serviços aos seus associados (LEI no 5.764, de 1971). Nos atos normativos baixados pelo Conselho Monetário Nacional (CMN) e pelo Banco Central (BACEN) as cooperativas de crédito são classificadas em: singulares, centrais ou federações, e confederações (BACEN, 2006).

No Brasil, atualmente, o sistema pioneiro de crédito cooperativo é composto de três macrosistemas - Sicoob, Sicredi e Unicred, vinculados a bancos com forma jurídica de sociedade anônima, o Bancoob S.A. e o Bansicredi S.A., aos dois primeiros sistemas citados, respectivamente. Um quarto sistema emergente está se concentrando especialmente no cooperativismo de crédito solidário, mencionado por Pinho e Palhares (2004); o sistema Cresol, Ecosol, Crehnor, Credtar e outros.

Por fim, observa-se que após a estagnação do cooperativismo, período anterior ao ano de 1995, tem ocorrido crescimento gradual (mas embora lento) concretizado atualmente por meio da cooperação advinda de pensamentos imaginários e idealizados durante a história deste movimento. Essas formas revelam a importância de pessoas se organizarem em torno de um objetivo comum, por intermédio de financiamento a baixo custo; melhoria da qualidade de vida aos participantes; além do retorno financeiro distribuído de forma democrática aos componentes e comunidades que as instituíram, os denominados associados.

\subsection{Conceituações de custos}

A interposição do Plano Contábil COSIF limitou consideravelmente a gestão estratégica das instituições financeiras, por normatizar somente a contabilização dos preceitos entre receitas e despesas. O planejamento de custos ficou a mercê de controles extra-contábeis. De fato, a mensuração de custos está intimamente ligada à indústria, o que não impossibilita a utilização de princípios e técnicas da Contabilidade 
Proposição de modelo para gestão de custos adicionais na concessão de empréstimo: o caso de cooperativas de crédito e o fator risco

Maicon Zanette, Cristiano Nascimento, Luiz Alberton

de Custos como ferramenta de controle e tomada de decisão em entidades nãoindustriais.

A dificuldade encontra-se na separação da quantia pertencente a custo e a parcela da despesa, uma vez que "[...] quando, à primeira vista, só existem despesas. Mas é fácil entender que a generalização dessa terminologia se deve não só ao uso das técnicas [...], como talvez principalmente à idéia de que tais entidades são produtoras de utilidades, e assim possuem custos" (MARTINS, 2003, p. 27).

Conforme explicitado por Sá (1995), há divergências conceituais sobre custos, sendo que os conflitos ocorrem por confundi-los como perdas e segregá-los nas despesas, considerados no conceito clássico como custos complementares. Nos dizeres do autor, custo é tudo o que se investe para conseguir um produto, um serviço ou uma utilidade (no sentido amplo); e que se entende por custos as aplicações para mover a atividade, seja direta ou indiretamente.

As cooperativas de crédito apresentam especificidades distintas às demais formas organizacionais que operam no sistema financeiro. Apresentam custos associados à participação, à gestão do empreendimento coletivo, e àqueles advindos das possíveis perdas decorrentes da fidelidade contratual ou de oportunismos dos agentes econômicos (BIALOSKORSKI NETO, 1999).

De acordo com o Conselho Federal de Contabilidade - CFC (2003), a Resolução CFC no 920, de 2001, que aprova a Norma Brasileira de Contabilidade Técnica, NBC T 10, que trata dos aspectos contábeis específicos em entidades diversas, tem no item NBC T 10.8, particularmente referente às entidades cooperativas cuja movimentação econômico-financeira decorrente do ato cooperativo na forma disposta no estatuto social, é definida contabilmente como ingressos e dispêndios, todavia, a movimentação econômico-financeira originada do ato não-cooperativo é definida como receitas, custos e despesas. Dito isso, ressalta-se o item NBC T 10.8.1.4.2 quanto aos custos dos produtos ou mercadorias fornecidos (vendidos) e dos serviços prestados, as despesas, os encargos e as perdas, pagos ou incorridos, são denominados dispêndios.

Conforme a NBC T 10.8.4.1, a Demonstração do Resultado passa a denominarse de Demonstração de Sobras ou Perdas, a qual deve evidenciar, de forma separada, 
Proposição de modelo para gestão de custos adicionais na concessão de empréstimo: o caso de cooperativas de crédito e o fator risco

Maicon Zanette, Cristiano Nascimento, Luiz Alberton

a composição do resultado de determinado período. Para isto, consideram-se "os ingressos diminuídos dos dispêndios do ato cooperativo, e das receitas, custos e despesas do ato não-cooperativo, demonstrados segregadamente por produtos, serviços e atividades desenvolvidas pela entidade cooperativa".

Naves (2007) assinala que as cooperativas de crédito dependem de uma série de fatores para o seu sucesso, como definição da taxa de juros para os empréstimos e de spreads adequados; baixa taxa de inadimplência; baixos custos de administração e capacidade de mobilização de poupança; entre outros.

A cooperativa de crédito possui custos de transação e custos operacionais. Os custos de transação são aqueles que envolvem a negociação, coleta de informações, monitoramento e enforcement legal, ou seja, são os custos que ocorrem antes da concessão do crédito. Os custos operacionais são os custos administrativos e os custos financeiros da instituição financeira. Ao tratar-se dos custos de transação, principalmente os de informação, a elaboração de contratos e a escolha de uma taxa de juros ótima apresentam relevante importância na concessão de crédito, principalmente no que diz respeito à avaliação de riscos. Tais características ampliam significativamente o custo relacionado a empréstimos de menor magnitude, principalmente àqueles destinados aos pequenos produtores rurais (NAVES, 2007).

Para Fachini (2005), os custos de transação compreendem todas as despesas que a instituição financeira possui. De forma complementar, explicita que as despesas financeiras referem-se aos custos de captação e de intermediação bancária; as despesas operacionais referem-se ao processo de recolhimento de informações sobre os clientes, além disso, soma-se o processo de monitoramento das atividades dos clientes; as despesas administrativas compreendem as despesas com aluguel, folha de pagamento, energia, telefone, etc; e as despesas com risco de crédito são aquelas referentes à qualidade de carteira de crédito da instituição.

Dentre as formas de enfrentar os problemas referentes ao crédito em cooperativas de crédito, Naves (2007) recomenda a utilização de mecanismos de seleção e monitoramento de clientes, que podem ser resumidos pela utilização de contratos complexos e exigência de garantias, entre outros controles burocráticos, que 
Proposição de modelo para gestão de custos adicionais na concessão de empréstimo: o caso de cooperativas de crédito e o fator risco

Maicon Zanette, Cristiano Nascimento, Luiz Alberton

implicam custos de transações mais altos, além dos operacionais. Porém, ressalta que tais custos podem influenciar nos desempenhos econômicos dessas instituições, impedindo, de certa forma, sua sustentabilidade financeira de longo prazo.

\subsection{Controle e riscos}

Durante um período da história da administração de empresas o conceito de controle contrapunha diversas formas e significados. Um especialista do setor de auditoria interna opinava diferentemente de um do setor de controladoria, que por sua vez não concordava com a visão de outro especialista. A necessidade de um conceito singular aumentava a confusão sobre o verdadeiro papel e significado dos controles em uma empresa.

O princípio do controle empresarial era exercido por apenas uma pessoa ou pequeno grupo. Este executivo era ao mesmo tempo o dono do negócio, preocupandose somente em cuidar e manter seus negócios na ativa para auto sustentar-se. Conforme Migliavacca (2002, p. 33), o primórdio da palavra controle surgiu por volta de 1600, como significado de "[...] cópia de uma relação de contas [...], um análogo com a sua origem da palavra em latim 'contrarotulus', que denota cópia do registro de dados $[\ldots] "$.

Nos dias atuais existe uma clara separação entre os que detêm a propriedade do negócio e os que realizam o controle de gestão. A complexidade empresarial exige a necessidade de especialistas em diferentes áreas funcionais. O controle é um método de fiscalização exercida sobre as atividades de pessoas, órgãos, departamentos, ou sobre produtos, entre outros, para que tais atividades, ou produtos, não se desviem das normas ou padrões preestabelecidos (FERREIRA, 1999).

Controle representa um dos quatro C's da qualidade total do modelo de gestão das cooperativas proposto por Oliveira (2003, p.92), que define controle como função do processo administrativo das cooperativas mediante comparação com padrões previamente estabelecidos, de forma que possam corrigir ou reforçar esse desempenho ou interferir em outras funções do processo administrativo das cooperativas, para assegurar que os resultados satisfaçam às metas e aos objetivos estabelecidos. 
Proposição de modelo para gestão de custos adicionais na concessão de empréstimo: o caso de cooperativas de crédito e o fator risco

Maicon Zanette, Cristiano Nascimento, Luiz Alberton

No passado, os conceitos sobre controle interno voltavam-se às atividades de contabilidade e finanças. Tais conceitos, na atualidade, não são tão bem aceitos. Como afirma Attie (1992), um sistema de controle interno bem desenvolvido pode incluir controle orçamentário, custos-padrão, relatórios operacionais periódicos, análises estatísticas, programas de treinamento do pessoal e, inclusive, auditoria interna; pode, também, abranger atividades em outros campos.

Todo controle implica exposição de riscos, torna-se quase que inevitável. Para Moore (1997 apud DACORSO, 2000), o risco trata de acontecimentos futuros e está presente na vida de todos e em diversas ocasiões. Sem assumir riscos é impossível um avanço econômico e até mesmo a manutenção do status quo.

De modo amplo, risco ocorre quando não se pode prever com certeza o resultado de uma alternativa, mas tem-se informação suficiente para prever a probabilidade de que ela irá levar à situação desejada. Difere da incerteza, pois pouco se sabe sobre as alternativas ou seus resultados.

Risco empresarial pode ser classificado, de acordo com Jorion (1999), como a volatilidade de resultados inesperados, normalmente relacionados ao valor de ativos. $\mathrm{O}$ mesmo autor afirma que as empresas estão expostas a três riscos: risco operacional (aqueles assumidos voluntariamente a fim de criar vantagem competitiva e valorizar a empresa perante seus acionistas); estratégico (resultante de mudanças fundamentais no cenário econômico ou político); e financeiro (ligado a possíveis perdas nos mercados financeiros). A gestão de risco financeiro tornou-se instrumento essencial para que uma atividade empresarial possa existir.

Por sua vez, o crédito, consiste na entrega de um bem ou de um valor presente mediante uma promessa de pagamento em data futura; enquanto essa promessa de pagamento perdurar a existência do risco também será iminente.

As razões que levam um cliente ao não-cumprimento da promessa de pagamento podem estar relacionadas ao seu caráter, a sua capacidade de gerir os negócios, fatores adversos ou a sua incapacidade de gerar caixa, a qual se considera primordial em análise por qualquer credor na liberação de recursos ou venda a um ou vários clientes. 
Proposição de modelo para gestão de custos adicionais na concessão de empréstimo: o caso de cooperativas de crédito e o fator risco

Maicon Zanette, Cristiano Nascimento, Luiz Alberton

Segundo Jorion (1999), o risco de crédito surge quando as contrapartes não desejam ou não são capazes de cumprir suas obrigações contratuais e, ainda, seu efeito é medido pelo custo de reposição de fluxos de caixa, caso a parte fique inadimplente.

Foi determinada para as instituições financeiras e demais instituições autorizadas a funcionar pelo BACEN por meio da Resolução n 2.682, de 1999, a classificação de cada operação de crédito em ordem crescente de risco, seguindo critérios de provisionamento contábil (a qual gera despesa de igual valor) face às perdas prováveis por parte de seus clientes, respeitados os prazos de inadimplemento em cada operação.

No caso de um devedor ficar 31 dias ininterruptos sem efetuar o pagamento, 3\% do saldo devedor da respectiva operação deverá ser provisionado em nível "C", e assim sucessivamente, como pode ser observado na Tabela 1 a seguir:

Tabela 1: Critérios de classificação para provisão das operações de crédito

\begin{tabular}{|c|c|c|}
\hline $\begin{array}{c}\text { Classificação } \\
\text { Nível de } \\
\text { Risco }\end{array}$ & Por Atraso & $\begin{array}{c}\text { Provisão } \\
\text { a } \\
\text { Constituir }\end{array}$ \\
\hline AA & -- & $0,00 \%$ \\
\hline A & $\begin{array}{c}\text { Normal ou atraso até 15 } \\
\text { dias }\end{array}$ & $0,50 \%$ \\
\hline B & Atraso entre 16 e 30 dias & $1,00 \%$ \\
\hline C & Atraso entre 31 e 60 dias & $3,00 \%$ \\
\hline D & Atraso entre 61 e 90 dias & $10,00 \%$ \\
\hline E & Atraso entre 91 e 120 dias & $30,00 \%$ \\
\hline F & Atraso entre 121 e 150 & $50,00 \%$ \\
\hline Gias & Atraso entre 151 e 180 \\
dias & $70,00 \%$ \\
\hline H & Atraso acima de 180 dias & $100,00 \%$ \\
\hline
\end{tabular}

Fonte: Adaptado de BACEN (1999)

Lemgruber et al. (2001) complementam que o risco de crédito pode ser dividido em três grupos: o risco do país, o risco político e o risco da falta de pagamento; entretanto, todos estão diretamente interligados com possíveis perdas de recursos que não serão mais recebidos. 
Proposição de modelo para gestão de custos adicionais na concessão de empréstimo: o caso de cooperativas de crédito e o fator risco Maicon Zanette, Cristiano Nascimento, Luiz Alberton

\section{METODOLOGIA}

O método empregado na presente pesquisa é de natureza exploratóriodescritiva, ao abordar o tema gestão de custos relacionados ao empréstimo pessoal aos associados de uma cooperativa de crédito. É caracterizada como exploratória pelo fato de haverem poucos estudos voltados a aplicação da proposição da mensuração de custos adicionais em função de empréstimo pessoal; e descritiva por explicitar procedimentos e etapas que antecedem a concessão do crédito.

Conforme Gil (1991), a aplicação de pesquisa descritiva combinada com pesquisa exploratória é habitualmente utilizada por pesquisadores sociais com foco de estudo voltado a atuação prática, condição que se identifica nesta pesquisa num esboço de relação teórico-empírica no uso e/ou aplicação da contabilidade nas práticas relacionadas à gestão de custos, com vistas a mensurar, por meio de provisão, os custos de avaliação e concessão de empréstimo pessoal e possíveis custos futuros.

$\mathrm{Na}$ busca de informações que subsidiassem a formulação deste estudo, fez-se necessário, na primeira fase da pesquisa, acompanhar as etapas de concessão de crédito aos associados de uma cooperativa de crédito sediada em Florianópolis, no Estado de Santa Catarina. Nesta fase predominou o método observacional sistemático com abordagem predominantemente qualitativa, no intuito de investigar procedimentos internos e práticas adotadas na ocasião em que um associado solicita empréstimo pessoal junto à cooperativa de crédito.

$\mathrm{Na}$ sua primeira fase o estudo foi de cunho descritivo caracterizado, conforme Marconi e Lakatos (1996), em uma abordagem de descrição, registro, análise e interpretação dos fenômenos atuais, objetivando o seu funcionamento no presente. $\mathrm{Na}$ segunda fase utilizou-se a técnica de simulação limitada a cálculos probabilísticos e matemáticos, no intuito da mensurar riscos inerentes ao processo de liberação de empréstimo pessoal combinado ao custo efetivo de tais riscos. Deste modo, nos preceitos de Dias e Corrêa (1998), a simulação tenta imitar matematicamente situações, a fim de estudar comportamentos e tirar conclusões para a tomada de decisão com base nos resultados obtidos, confrontando-se com a realidade empresarial. 
Proposição de modelo para gestão de custos adicionais na concessão de empréstimo: o caso de cooperativas de crédito e o fator risco

Maicon Zanette, Cristiano Nascimento, Luiz Alberton

Nesse sentido, destaca-se que para efeito de simulação esta técnica possibilita, através de experimentos teóricos, estudar prováveis comportamentos da entidade envolvida ou ao menos propõe um modelo de forma simplificada para a gestão eficiente de custos, em processos de serviços financeiros a partir da mensuração dos riscos inerentes.

A partir de conceitos de Santos (1992), este estudo permite avaliar por meio de análises os resultados que serão encontrados em situações reais, ampliando a compreensão do comportamento de sistemas ou mesmo avaliar as estratégias frente a fatos dos quais não se consegue vislumbrar os resultados finais ou a totalidade de suas implicações, se não por meio da simulação.

\section{ESQUEMA SINÓPICO DAS OPERAÇÕES DE CRÉdITO E OS RISCOS INERENTES}

Os produtos e serviços oferecidos pelas cooperativas de crédito acarretam riscos a eles associados. Presume-se que alguns riscos são comumente inerentes aos produtos negociados nas instituições financeiras, outros por sua vez dependem exclusivamente da particularidade de cada entidade e de seus processos.

Considerando as peculiaridades de cada produto, deve se considerar individualmente seus riscos em termos de possibilidade de ocorrência, potencial impacto monetário e a hipótese do que fazer para eliminá-lo ou torná-lo mínimo, no intuito principal da redução de custos e prováveis perdas decorrentes do inadimplemento.

Os procedimentos constantes no fluxo de concessão de empréstimo pessoal e seus riscos inerentes principais, identificados a partir da primeira fase da pesquisa, são visualizados na Figura 1.

A concessão de empréstimo pessoal inicia no setor de atendimento da cooperativa onde o associado solicita o crédito; caso necessário subordina-se a entrega de documentos requeridos pelo atendente. Inicialmente, procede-se uma breve 
Proposição de modelo para gestão de custos adicionais na concessão de empréstimo: o caso de cooperativas de crédito e o fator risco

Maicon Zanette, Cristiano Nascimento, Luiz Alberton

entrevista com o associado a fim de averiguar algumas informações e o objetivo da solicitação do crédito.

Neste momento incide o risco da idoneidade do tomador de crédito, que por meio de análise criteriosa sobre o perfil do proponente e a finalidade do crédito busca-se evitar custos futuros. Torna-se oportuno ao responsável pelo atendimento analisar a compatibilidade dos documentos envolvidos na negociação, consultas internas e externas (no SERASA, SPC, outros), atualização do cadastro, a fim de averiguar a capacidade de pagamento e parcelas envolvidas.

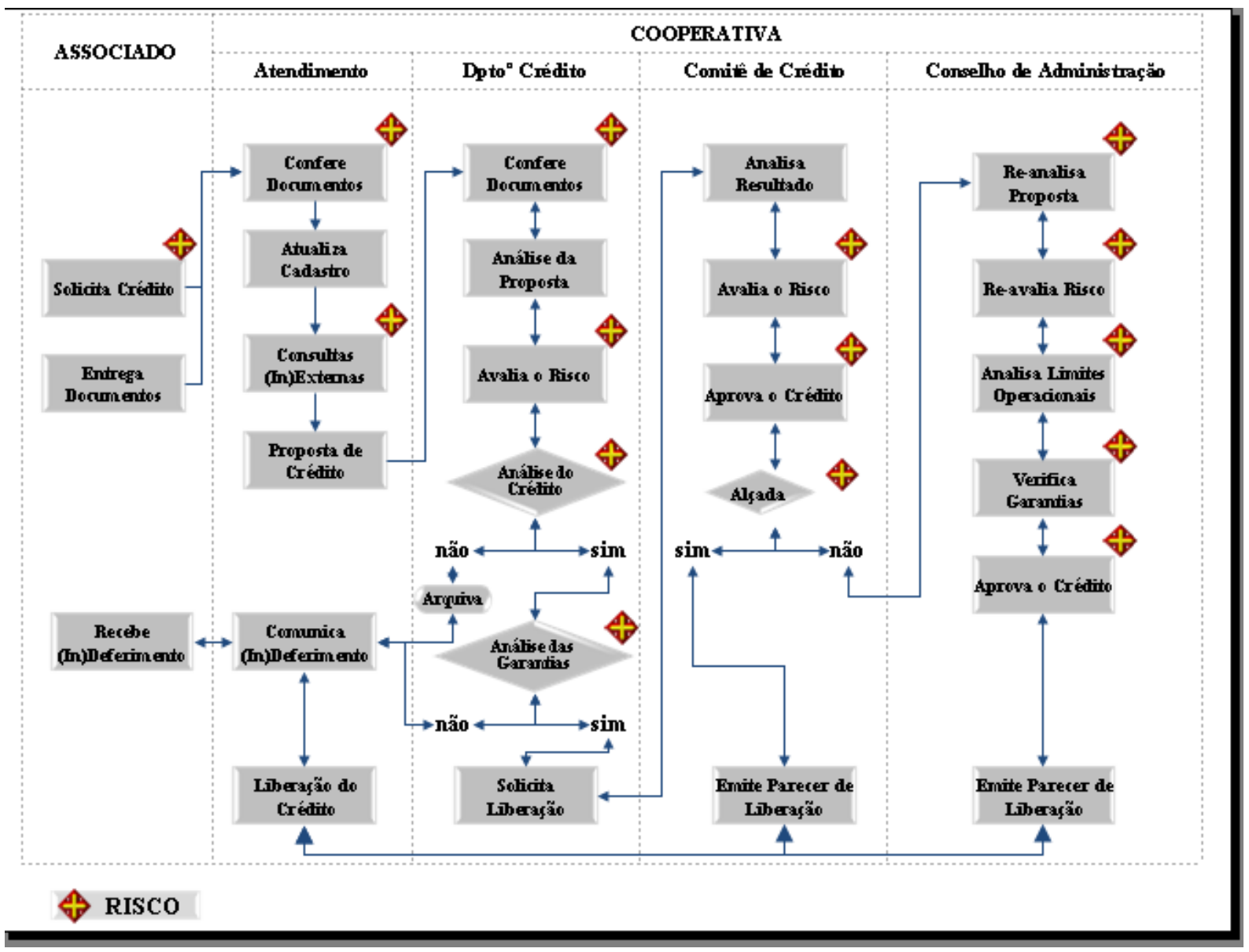

Figura 1: Fluxo da concessão de empréstimo pessoal e os riscos inerentes. Fonte: Dados da Pesquisa.

Havendo incompatibilidade entre a situação econômico-financeira do proponente e o valor das parcelas, podem ser evitados custos monetários futuros que muitas vezes advém do inadimplemento, que afeta diretamente as operações de crédito por meio da 
Proposição de modelo para gestão de custos adicionais na concessão de empréstimo: o caso de cooperativas de crédito e o fator risco

Maicon Zanette, Cristiano Nascimento, Luiz Alberton

provisão para operações de crédito (conta redutora daquelas), que por sua vez compromete o resultado da cooperativa.

O departamento de crédito na cooperativa é a área responsável por análises técnicas das propostas, devendo confirmar a confiabilidade dos documentos, avaliar o grau de classificação do risco alocado ao proponente e a operação de crédito solicitada.

Considera-se de fundamental importância a análise criteriosa neste momento para que o processo de liquidação ocorra normalmente, uma vez que o enquadramento adequado do perfil do associado perante a sua necessidade de crédito, bem como as exigências internas da cooperativa para cada linha de crédito solicitado, não venham a se tornar riscos e custos.

Quanto ao limite de empréstimo pessoal, além das tratativas de informações contidas no dossiê de crédito, são analisados os limites operacionais da cooperativa normatizados por regras do BACEN, como é o caso do limite de diversificação de risco por devedor para concessão de operações de crédito e prestação de garantias não excedente a $15 \%$ e $10 \%$ do Patrimônio de Referência (PR), respectivamente a cooperativas filiadas e conveniadas a um sistema organizado de Cooperativas.

Os aspectos relacionados aos tipos de garantias dependem de avaliação criteriosa dos documentos, a fim de averiguar a sua idoneidade no caso de garantia pessoal, e a cobertura do valor do bem para com as operações contratadas, em relação a garantia real.

A cada nova operação de crédito atribui-se classificação de risco de provisionamento contábil, conforme prevê a Resolução n² 2.682/1999 do BACEN, entretanto, os critérios de atribuição por parte dos departamentos não deve ser aleatório, pois são avaliados fatores internos e externos à cooperativa, bem como aspectos do associado, tipo de operação, garantias, entre outros fatores.

Tornam-se coerentes, em meio à avaliação do risco, as indagações técnicas acerca dos pontos fracos e fortes na recomendação ou não da concessão do crédito por parte do departamento e do Comitê de Crédito. Este último, segundo sua alçada de competência, emite parecer de liberação após as análises mencionadas. 
Proposição de modelo para gestão de custos adicionais na concessão de empréstimo: o caso de cooperativas de crédito e o fator risco

Maicon Zanette, Cristiano Nascimento, Luiz Alberton

No entanto, dependendo da operação de crédito e do associado, faculta-se ao Presidente (por poder impositivo e ditatório) ou ao Conselho de Administração a decisão final. Nota-se, neste momento, o artifício da "influência" predominante no cooperativismo de crédito, o que compromete todo o esquema de inferência de custos sugerido no próximo tópico.

O poder de barganha e autoridade predominante dos associados para com os gestores das cooperativas, bem como o colaborador de cargos estratégicos, influencia diretamente no processo de análise criteriosa de concessão do empréstimo. Esta influência se dá mediante beneficiamento de juros, abstenção de garantias, limites de crédito além do permitido, facilidade no parcelamento, entre outros.

\section{INFERÊNCIA DOS CUSTOS AO ESQUEMA ALUDIDO}

O pressuposto da terminologia de 'custos' em entidades não industriais, como no caso das cooperativas de crédito, confunde-se com a terminologia da 'despesa' imposta por normas vigentes e o COSIF. Mas ressalta-se que a produção de serviços financeiros, de acordo com Martins (2003, p.27), incorre "[...] custos que imediatamente se transformam em despesas, sem que haja a fase de Estocagem, como no caso da indústria de bens, mas de qualquer forma não deixa de ser apropriada a terminologia. Portanto, é perfeitamente idêntica a terminologia nessas empresas."

Considere-se um caso hipotético na concessão de crédito no montante de $R \$ 15.000,00$, cuja classificação no nível de provisionamento contábil em "B", de acordo com preceitos da Resolução $n^{\circ} 2.682 / 1999$, resultou $R \$ 150,00$ de despesas para a cooperativa. O "Custo Adicional de Provisão" foi calculado em relação à dedução das atividades identificadas particularmente ao processo de liberação de empréstimo pessoal, e de acordo com os riscos inerentes mensurados no fluxo mostrado anteriormente (Figura 1).

No cálculo da inferência dos custos adotou-se um indicador para a quantidade de atividades mensuradas (total de 9). Em relação aos custos (fator risco) respeitou-se a quantificação classificatória imposta pela Resolução n².682/1999 do BACEN, cuja 
Proposição de modelo para gestão de custos adicionais na concessão de empréstimo: o caso de cooperativas de crédito e o fator risco

Maicon Zanette, Cristiano Nascimento, Luiz Alberton

alocação se dá por critérios qualitativos (a experiência do analista de crédito e a vivência do associado perante a cooperativa), em detrimento ao grau de riscos inerentes.

Após mensurar os custos prováveis de riscos, submetidos no exemplo à classificação "AA" para as atividades consideradas básicas e identificadas pelo setor de crédito como sendo "risco zero", ou seja, não interferiu efetivamente na concessão do crédito; calcula-se o custo efetivo do risco, também, analogamente na proporção das atividades mensuradas.

A atividade "Avaliação do Risco" classificada sob custo no nível de risco "B", resulta em um custo risco de $R \$ 1,85((\mathrm{R} \$ 15.000,00 \times 1 \div 9 \times 1,00 \%) \div 9)$ e, assim, sucessivamente é calculado a inferência de todas as atividades identificadas no processo de liberação de empréstimo pessoal.

Em termos gerenciais as atividades utilizadas para a geração do serviço "empréstimo pessoal" são consideradas, em parte, como custos que se tornarão imediatamente despesas. Contudo, conforme explanação de Martins (2003), quando se fala "Contabilidade de Custos", refere-se apenas aos bens ou serviços utilizados na produção de outros bens e serviços.

Portanto, a suposição considerada no presente modelo torna-se necessária para fins de controle gerencial dos custos inerentes às atividades desenvolvidas em processos de serviços financeiros, uma vez que a contabilização efetiva de tais 'custos' somente será respaldada legalmente por meio de lançamentos em contas de despesa, impostas por normativas do BACEN.

As contas envolvidas nos lançamentos do "Custo Adicional de Provisão" são: conta redutora do ativo "1.6.9.00.00-8 (-) Provisão para Operações de Crédito" em desdobramentos de subgrupo contábil de uso interno a critério de cada instituição. Como exemplo, recomenda-se "1.6.9.97.00-4 (-) Provisão para Perdas na Realização de Operações de Crédito", a qual tem por função, conforme Carta-Circular no 2.899/2000 do BACEN, registrar valores provisionados decorrentes da classificação das operações nos diferentes níveis de risco em função das características do devedor e seus garantidores, bem como da operação. 
Proposição de modelo para gestão de custos adicionais na concessão de empréstimo: o caso de cooperativas de crédito e o fator risco

Maicon Zanette, Cristiano Nascimento, Luiz Alberton

De acordo com a Circular $n^{\circ} 1.962 / 1991$ do BACEN, observa-se que a constituição destas provisões deve caracterizar reais condições de liquidez de cada uma das operações, de modo que a mesma reflita adequadamente as perdas potenciais na carteira de crédito, independentemente de limites fiscais. Nestes preceitos, justifica-se a identificação criteriosa alocada pelos analistas de crédito da cooperativa ao atribuir as ponderações de níveis aos custos (coluna fator risco).

O controle do "Custo Adicional de Provisão" deve-se ao fato enunciado na Circular $n^{\circ} 2.461 / 1994$, em seu artigo $1^{\circ}, \S 2^{\circ}$, a qual obriga provisão para fazer face à perdas permanentes, efetivas ou potenciais, tendo como contrapartida conta de natureza devedora sob o título "8.1.8.30.00-0 Despesas de Provisões Operacionais" subtítulo "8.1.8.30.99-0 Outras Despesas de Provisões Operacionais".

A reversão do custo deverá obedecer à seguinte sistemática: débito no subtítulo contábil "1.6.9.97.00-4 (-) Provisão para Perdas na Realização de Operações de Crédito" e crédito da rubrica contábil "7.1.9.90.00-8 Reversão de Provisões Operacionais" subtítulo "7.1.9.90.99-8 Outras".

Adverte-se que o registro da reversão do provisionamento do custo somente poderá ocorrer com a quitação por absoluto da operação de crédito pessoal por parte do devedor, e nunca por intermédio de renegociação. A sistemática de cálculo e o fluxo contábil podem ser observados no Quadro 1.

A liberação de empréstimo pessoal tem seu prazo estipulado, geralmente, por no mínimo 6 meses, mas caso o mesmo tenha sua concessão inferior a este prazo recomenda-se a liberação na forma de "Crédito Consignado" (o chamado desconto em folha de pagamento), pois a ponderação do fator risco em cada atividade implicará em níveis mínimos.

Destarte, evidencia-se o constante na Circular $n^{\circ} 1.273 / 1987$ quanto ao registro das reversões na rubrica contábil "7.1.9.90.00-8", ou seja, deve se registrar as reversões de provisões constituídas em exercícios ou semestres anteriores. Este título “[...] não é adequado para registrar as reversões de provisões constituídas para atender a apropriação mensal de despesas, cujos acertos se fazem por estorno da despesa correspondente ou complemento da provisão, se for o caso." 
Proposição de modelo para gestão de custos adicionais na concessão de empréstimo: o caso de cooperativas de crédito e o fator risco

Maicon Zanette, Cristiano Nascimento, Luiz Alberton

Em virtude de limitações legais impostas na criação de rubricas contábeis no plano de contas conforme determina o COSIF, recomenda-se o acompanhamento extra-contábil por meio de planilhas, as quais permitirão o desdobramento da conta “1.6.9.97.00-4 (-) Provisão para Perdas na Realização de Operações de Crédito" e, por conseguinte, a despesa "8.1.8.30.99-0 Outras". Mediante este mecanismo são controladas as ocorrências de custo nominalmente por associado bem como por operação.

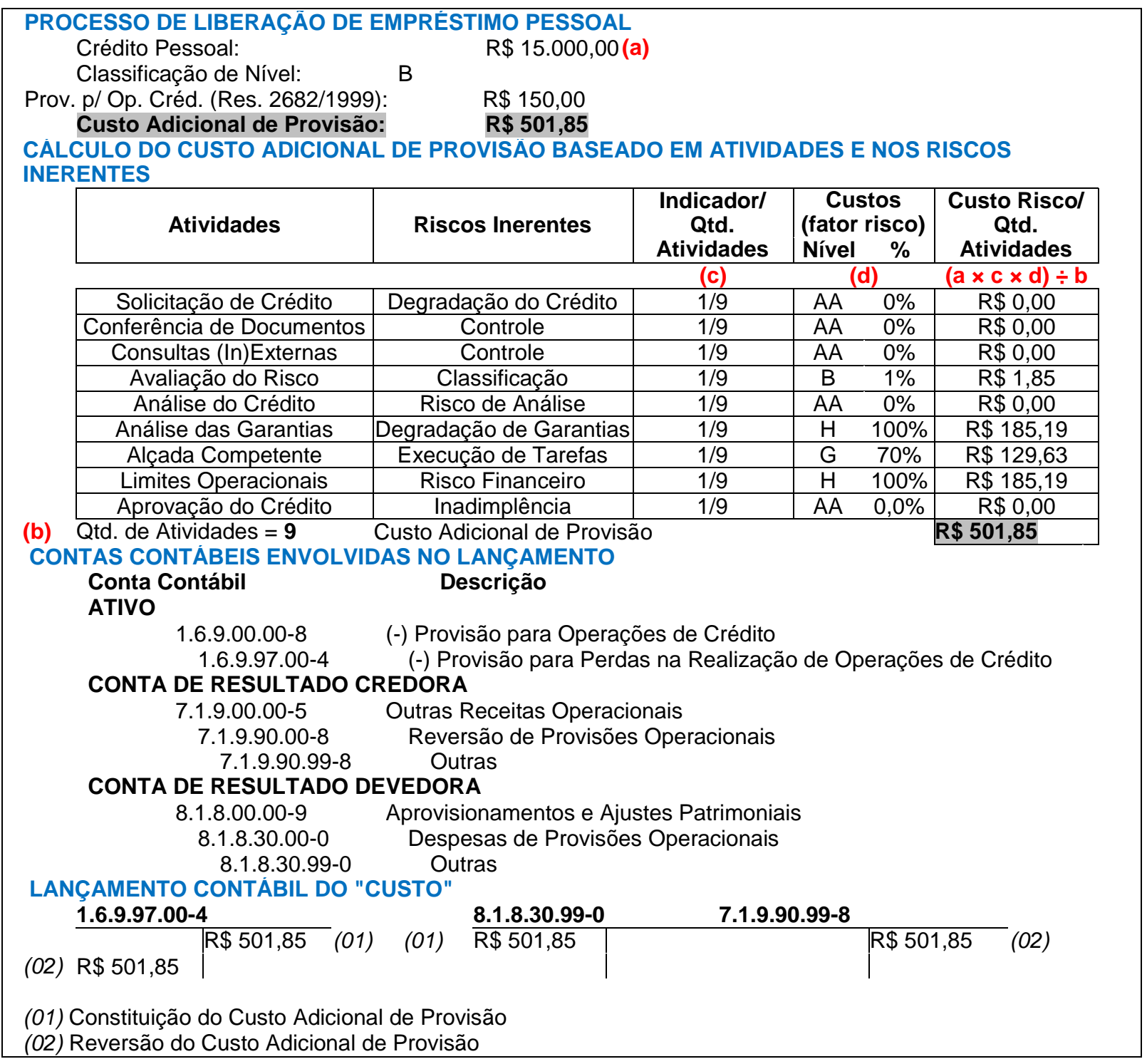

Quadro 1: Sistemática de cálculo e fluxo contábil Fonte: Dados do estudo 
Proposição de modelo para gestão de custos adicionais na concessão de empréstimo: o caso de cooperativas de crédito e o fator risco

Maicon Zanette, Cristiano Nascimento, Luiz Alberton

A constituição de provisão excedente visa à cobertura de futuros gastos decorrentes principalmente do inadimplemento das operações de crédito superiores a seis meses no mínimo (conforme prevê a Circular n 1.273/1987). No caso de custas judiciais no processo de cobrança de saldos em prejuízo, estas despesas administrativas podem ser amenizadas por meio da reversão de provisão constituída inicialmente, conforme método explanado (Quadro 2).

\begin{tabular}{|c|c|c|}
\hline $7.1 .9 .00 .00-5$ & OUTRAS RECEITAS OPERACIONAIS & \\
\hline $7.1 .9 .90 .00-8$ & REVERSÃO DE PROVISÖES OPERACIONAIS & \\
\hline $7.1 .9 .90 .99-8$ & Outras & $\mathrm{R} \$ \quad 7.000,00$ \\
\hline $8.1 .7 .00 .00-6$ & DESPESAS ADMINISTRATIVAS & \\
\hline $8.1 .7 .63 .00-5$ & DESPESAS DE SERVIÇOS TÉCNICOS ESPECIALIZADOS & \\
\hline & Consultoria Jurídica & $\mathrm{R} \$(10.000,00)$ \\
\hline & Recursos a cobrir & $\mathbf{R} \$(\mathbf{3 . 0 0 0}, 00)$ \\
\hline
\end{tabular}

Quadro 2: Reversão para cobertura de custos adicionais Fonte: Dados do Estudo.

Conforme o exposto no Quadro 2, o saldo de $\mathrm{R} \$ 10.000,00$ reconhecido como despesas de serviços técnicos especializados em consultoria jurídica (processo de cobrança judicial), pode ser amenizado com a reversão contábil da provisão excedente conforme método de cálculo do "Custo Adicional de Provisão", que no caso é de $\mathrm{R} \$ 7.000,00$, atenuando contabilmente o resultado da cooperativa.

A estrutura de cálculo proposta visa à prevenção de perdas permanentes, efetivas ou potenciais que possam ocorrer aos processos financeiros das cooperativas de crédito. Acredita-se que a utilização do "Custo Adicional de Provisão" consolida-se num modelo de proposição para mensurar custos na concessão das operações de crédito e os riscos futuros que possam ocorrer advindos fundamentalmente do inadimplemento.

Por fim, a partir da proposição de controles extra-contábeis, "custos adicionais de provisão", para avaliação e concessão em operações de empréstimo pessoal, busca-se contribuir na gestão eficiente dos custos em uma cooperativa de crédito. Deste modo, a instituição poderá ampliar o controle sobre os custos gerados e os que poderão vir a ocorrer, de forma complementar a toda obrigatoriedade imposta por normas que regulam a contabilização do setor financeiro. 
Proposição de modelo para gestão de custos adicionais na concessão de empréstimo: o caso de cooperativas de crédito e o fator risco Maicon Zanette, Cristiano Nascimento, Luiz Alberton

\section{CONCLUSÃO}

Este estudo tem como base de análise a condição de concessão de empréstimo pessoal no ambiente institucional de uma cooperativa de crédito com vistas à proposição de um modelo de mensuração para custos adicionais, o qual deve gerar como benefício, em termos de gestão, a prevenção de perdas financeiras. Para tal, são explicitadas eventuais atividades e riscos que envolvem o conjunto de operações relacionadas ao crédito.

Conforme mencionado, o Plano Contábil COSIF limita a gestão estratégica das instituições financeiras, fato que atinge diretamente as cooperativas de crédito, pois tal plano contábil orienta, por meio de normas, somente a contabilização dos preceitos entre receitas e despesas. Neste contexto, o planejamento de custos fica a critério de controle extra-contábil, condição que depende do interesse da instituição financeira desejar ter controle sobre tais custos, ou seja, ter controle sobre os custos de transação e custos operacionais.

As cooperativas de crédito possuem custos organizacionais relacionáveis a gestão do empreendimento coletivo combinados com outros de atividades afins, como os custos inerentes a concessão de empréstimo pessoal. Neste contexto, utiliza-se a contabilização permitida nas normas vigentes, já que o empréstimo pessoal consiste basicamente na disponibilização de recurso financeiro ao cliente mediante uma promessa de pagamento em data futura. Logo, até que o cliente encerre a dívida, a existência do risco do não recebimento persiste, mesmo que em condições mínimas.

Deste modo, a proposição do presente modelo torna-se relevante para fins de controle gerencial dos custos existentes nas atividades desenvolvidas em processos de serviços financeiros. Portanto, a partir do esquema proposto, explicitado no Quadro 1, em função da liberação do empréstimo pessoal, propõe-se a contabilização com abordagem direcionada a gestão de custos.

Ressalta-se a obrigatoriedade de provisionamento frente à possibilidade de perdas futuras, porém, a conta destinada, conforme COSIF, se denomina "despesas de provisões operacionais". A isto, somam-se limitações na impossibilidade de criar 
Proposição de modelo para gestão de custos adicionais na concessão de empréstimo: o caso de cooperativas de crédito e o fator risco

Maicon Zanette, Cristiano Nascimento, Luiz Alberton

rubricas contábeis no plano contábil previsto no COSIF, sugerindo-se como alternativa a criação de planilhas de controle extra-contábil.

Pelo fato de todas as práticas e operações executadas antes da concessão efetiva do empréstimo constituir custos de transação, tem-se no "custo adicional de provisão" a possibilidade de mensurar os custos gerados em função da concessão de crédito, assim como prevenir-se de custos futuros advindo do fator risco, principalmente no caso de não recebimento dos recursos contratados no momento em que fora firmada a operação de crédito. Logo, por meio desse mecanismo torna-se possível o controle das ocorrências de custos de forma nominal por associado e/ou por operação.

A gestão dos custos em conta específica denominada "custo adicional de provisão", permite a cada instituição cooperativista de crédito dimensionar a representatividade dos custos em suas operações, ao mesmo tempo em que poderá contar com base informacional importante para posicionar-se sobre a relevância ou não do volume de custos gerados nas operações de controle, por ocasião das etapas que envolvem a concessão de empréstimo pessoal, comparativamente aos custos futuros.

Por fim, ressalta-se que a menção do modelo e os preceitos propostos não estabelecem, precisamente ou em sua totalidade, uma referência absoluta na gestão de custos em cooperativas de crédito, pois a concessão do crédito, por vezes, segue caminhos distintos das práticas explicitadas neste estudo. Mas, sem dúvida, a proposição da utilização do "Custo Adicional de Provisão" constitui ferramenta para adaptações e aprimoramentos de acordo com as necessidades de cada cooperativa, com vistas a um controle maior dos custos que incorrem na avaliação e concessão do crédito.

\section{REFERÊNCIAS}

ATTIE, W. (1992). Auditoria Interna. São Paulo: Atlas.

BANCO CENTRAL DO BRASIL - BACEN. Carta-Circular n. 2.899 de 01 de março de 2000. Altera no COSIF procedimentos para registro das operações de crédito e constituição de provisão para fazer face aos créditos de liquidação duvidosa. Disponível em: <http://www5.bcb.gov.br/normativos/principal.asp>. Acesso em: 20/novembro/2008. 
Proposição de modelo para gestão de custos adicionais na concessão de empréstimo: o caso de cooperativas de crédito e o fator risco

Maicon Zanette, Cristiano Nascimento, Luiz Alberton (2006). Cooperativas de Crédito. Brasília: BCB, 118 p.

. Circular n. 1.273 de 29 de dezembro de 1987. Institui Plano Contábil das Instituições do Sistema Financeiro Nacional - COSIF. Disponível em: <http://www5.bcb.gov. br/normativos/principal.asp>. Acesso em: 20/junho/2008.

. Circular n. 2.461 de 10 agosto de 1994. Dispõe sobre o registro contábil de imóveis que não se destinem à manutenção da atividade das administradoras de consórcio. Disponível em: <http://www5.bcb.gov.br/normativos/principal.asp>. Acesso em: 20/junho/2008.

. Resolução n. 2.682 de 21 de dezembro de 1999. Dispõe sobre critérios de classificação das operações de credito e regras para constituição de provisão para créditos de liquidação duvidosa. Disponível em: <http://www5.bcb.gov.br/normativos/principal.asp>. Acesso em: 10/março/2009.

BIALOSKORSKI NETO, S. (1999). A Nova Geração de Cooperativas e a Coordenação de Sistemas Agroindustriais. In: II Workshop Brasileiro De Gestão De Sistemas Agroalimentares, Anais... Ribeirão Preto: PENSA/FEA/USP.

BRASIL. Lei n. 5.764, de 16 de dezembro de 1971. Define a Política Nacional de Cooperativismo, institui o regime jurídico das sociedades cooperativas, e dá outras providências. Disponível em: <http://www.planalto.gov.br/CCIVIL/leis/L5764.htm>. Acesso em: 05/dezembro/2008.

CONSELHO FEDERAL DE CONTABILIDADE - CFC. (2003). Princípios fundamentais e normas brasileiras de contabilidade. Brasília: CFC, 202p.

DACORSO, A.L.R. (2000). Tomada de Decisão e Risco: A administração da inovação em pequenas indústrias químicas. (Dissertação de Mestrado). Faculdade de Economia, Administração e Contabilidade, São Paulo, SP, 236f. Disponível em: $<$ http://www.teses.usp.br/teses/disponiveis/12/12139/tde-04032005-151150/>. Acesso em: 10/novembro/2008.

FACHINI, C. (2005). Sustentabilidade financeira e custos de transação em uma organização de microcrédito no Brasil. (Dissertação de Mestrado). Escola Superior de Agricultura Luiz de Queiroz, Universidade de São Paulo, Piracicaba, SP, $150 \mathrm{f}$. Disponível em: <http://www.teses.usp.br/teses/disponiveis/ 11/11132/tde-03062005155034/>. Acesso em: 10/julho/2008.

FERREIRA, A.B.H. (1999). Novo Aurélio Século XXI: O dicionário da língua portuguesa. (3 ed.). Rio de Janeiro: Nova Fronteira.

GIL, A.C. (1991). Como elaborar projetos de pesquisa. (3 ed.). São Paulo: Atlas. 
Proposição de modelo para gestão de custos adicionais na concessão de empréstimo: o caso de cooperativas de crédito e o fator risco

Maicon Zanette, Cristiano Nascimento, Luiz Alberton

JORION, P. (1999). Value At Risk: A nova fonte de referência para o controle do risco de mercado. São Paulo: BM\&F.

JUNQUEIRA, L.A.P.; TREZ, A.P. (2005). Capital Social e a Sobrevivência das Cooperativas de Trabalho. Revista de Administração Pública, v. 39, n. 2, mar./abr., p. 381-400.

LEMGRUBER, E.F.; et al. (2001). Gestão de Risco e Derivativos: Uma aplicação no Brasil. São Paulo: Atlas.

MARCONI, M.A.; LAKATOS, E.M. (1996). Técnicas de Pesquisa: Planejamento e execução de pesquisas, elaboração, análise e interpretação de dados. São Paulo: Atlas.

MARTINS, E. (2003). Contabilidade de Custos. São Paulo: Atlas.

MIGLIAVACCA, P.N. (2002). Controles internos nas organizações. São Paulo: Edicta.

MOORE, P.G. (2000). The Business Of Risck. In: DACORSO, A.L.R. Tomada de Decisão e Risco: A administração da inovação em pequenas indústrias químicas. (Dissertação de Mestrado). Faculdade de Economia, Administração e Contabilidade, São Paulo, SP, 236f. Disponível em: <http://www.teses.usp.br/teses/disponiveis/12/12139/tde-04032005-151150/>. Acesso em: 10/novembro/2008.

NAVES, C.F.B. (2007). A sustentabilidade financeira das cooperativas de crédito rural: um estudo de caso no estado de São Paulo. (Dissertação de Mestrado). Faculdade de Economia Administração e Contabilidade de Ribeirão Preto, Universidade de São Paulo, Ribeirão Preto, 145f. Disponível em: $<$ http://www.teses.usp.br/teses/disponiveis/96/96131/tde-17072007-150840/>. Acesso em: 10/julho/2008.

OLIVEIRA, D.P.R. (2003). Manual de Gestão das Cooperativas: Uma abordagem prática. (2 ed.). São Paulo: Atlas.

ORGANIZAÇÃO DAS COOPERATIVAS DO ESTADO DE SANTA CATARINA OCESC. (2004). O Cooperativismo ao Alcance de Todos. Santa Catarina: SESCOP.

PINHO, D.B. (1976). Doutrina Cooperativista. São Paulo: DAC/SAESP/INESP.

PINHO, D.B.; PALHARES, V.M.A. (Org.). (2004). O Cooperativismo de Crédito no Brasil: do século XX ao século XXI. São Paulo: Confebrás, Edição comemorativa.

RICHARDSON, R.J. (1999). Pesquisa Social: Métodos e técnicas. São Paulo: Atlas. 
Proposição de modelo para gestão de custos adicionais na concessão de empréstimo: o caso de cooperativas de crédito e o fator risco Maicon Zanette, Cristiano Nascimento, Luiz Alberton

SÁ, A.L. (1995). Custo da qualidade total. IOB Temática Contábil e Balanços. São Paulo, n. 2. p.12-16.

SIQUEIRA, O.G. (2001). A Crise das Grandes Cooperativas: um estudo comparado entre a cooperativa de Carazinho (RS) e a de Não-me-toque (RS). Dissertação de Mestrado. Universidade Federal do Rio Grande do Sul, Porto Alegre, RS, $217 f$. Disponível em: <http://www.biblioteca.ufrgs.br/ bibliotecadigital/>. Acesso em: 04/abril/2008.

Data de Submissão: 07/04/2009

Data de Aceite: 14/04/2009 